\title{
THE USE OF SODIUM HYPOBROMITE FOR THE OXIDATION OF ORGANIC MATTER IN THE MECHANICAL ANALYSIS OF SOILS.
}

\author{
BY ERIK TROELL. \\ (Chemistry Department, Rothamsted Experimental Station, Harpenden.)
}

THE pipette method of mechanical analysis requires the preparation of a completely dispersed soil suspension and G. W. Robinson has shown that with ammonia as the dispersing agent, even after the removal of calcium carbonate and exchangeable calcium, it is not possible to disperse certain soils rich in organic matter. He therefore proposed the removal of the greater part of this organic matter by a preliminary oxidation by hydrogen peroxide in boiling solution. His method proved so successful that it was adopted as the official method of the International Society of Soil Science in Conferences at Rothamsted in 1926, and in Washington in 1927. Difficulties were encountered later in several countries and at the Prague Conference of the First Commission of the International Society in 1929 it was decided to re-examine the whole question of pretreatment of soils for mechanical analysis.

Apart from readily dispersed soils in which a preliminary oxidation is probably unnecessary, the principal difficulties have been that hydrogen peroxide is an expensive and troublesome reagent in the tropics, and that in some soils the peroxide is decomposed so rapidly by catalysis by manganese dioxide that it is extremely tedious if not impossible to complete the oxidation of organic matter. L. B. Olmstead, L. T. Alexander and H. E. Middleton(1) have modified the method by conducting the hydrogen peroxide oxidation in the presence of acetic acid which destroys the manganese dioxide and allows the oxidation of organic matter to proceed.

The use of acid and the prolonged boiling are objected to by some workers, especially as the oxidation is accompanied by the solution of relatively large amounts of iron and aluminium, and it is not clear whether these come from the organic matter or from the decomposition of inorganic colloids.

To overcome both types of objection to the hydrogen peroxide method the use of cold solutions of sodium hypobromite was examined 
and gave good results. Subsequently it was found that A. Atterberg (2) had also used this method but had not developed it. A solution of sodium hypobromite causes rapid oxidation of the soil organic matter in the cold and in the presence of manganese dioxide, whether naturally occurring in the soil or added in amounts up to one-quarter of the weight of soil. Some black African soils were decolorised in a few minutes, whereas they remained black for hours in boiling solutions of hydrogen peroxide. No appreciable amounts of inorganic matter were dissolved. The traces of aluminium were much smaller than those making up the so-called "Loss on solution" in the hydrogen peroxide method.

Subsequently it was found that by using sodium hypobromite it was possible to effect considerable simplification and saving of time in mechanical analysis by comparison with the official hydrogen peroxide method. No acid treatment is required and addition of ammonia as a deflocculating agent is unnecessary; shaking may be reduced from 24 hours to 30 minutes in a mechanical shaker or may even be restricted to a vigorous shaking by hand for most soils.

\section{EXPERIMENTAL.}

The method as finally developed and tested on a number of soils, some of which were difficult to disperse by older methods, is as follows:

$10 \mathrm{gm}$. of air dry soil are treated with 200 c.c. of a freshly prepared solution of sodium hypobromite obtained by adding 2.5 c.c. of bromine to 100 c.c. of cold $\mathrm{N} \mathrm{NaOH}$. The bromine may be measured in a small cylinder containing a few c.c. of water or, more conveniently where many determinations are made, from a special bromine burette in which the mouth is closed by a ground-in glass cock. On shaking the bromine and sodium hydroxide solution for a few seconds the bromine dissolves and the solution is ready for immediate use: 100 c.c. are added to the soil and the mixture shaken occasionally. After about 2 hours a second lot of 100 c.c. of sodium hypobromite is added and the mixture is allowed to stand overnight. For average soils without large amounts of organic matter oxidation for 4 or 5 hours has proved sufficient.

After the oxidation sufficient dilute ammonia is added to destroy excess hypobromite which would otherwise attack the filter paper. The soil is collected on a hard filter paper (such as Whatman's No. 50) and washed with about 100 c.c. of (roughly) $N \mathrm{NaCl}$ and then with $0 \cdot 1 \mathrm{~N}$ $\mathrm{NaCl}$. For soils with much organic matter the filtrate sometimes has a dark colour. Washing with $0.1 \mathrm{~N} \mathrm{NaCl}$ is continued until the filtrate is colourless. A final washing is made with about 50 c.c. of distilled water, 


\section{Sodium Hypobromite Method for Mechanical Analysis}

but this may be reduced or omitted if water dropping from the filter funnel becomes turbid. The soil is transferred to a long cylinder and diluted to 500 c.c.

After mechanical shaking for 30 minutes the clay fraction and the clay + silt fraction are removed and weighed in the usual pipette technique. Most of the supernatant liquid is poured off and the sediment washed through a $0.2 \mathrm{~mm}$. sieve (or one with 100 meshes to the inch) into a tall 400 c.c. beaker. The sand on the sieve is washed with a stream of distilled water, collected, and weighed as the coarse sand fraction. The fine sand fraction is freed from silt and clay by repeated decantations. The removal of coarse sand after the shaking and the pipette samplings instead of before them, as in the official method, has the advantages of eliminating irregularities from rubbing the whole of the soil mass on the sieve and of giving much cleaner sand fractions. Discrepancies in the results obtained in different laboratories have been traced to the retention of varying amounts of clay and silt particles as aggregates in the coarse sand fraction obtained in the usual way. The use of a tall column of suspension in a narrow beaker increases the accuracy and reproducibility of the separation of silt from fine sand. In the sodium hypobromite method there is no necessity to determine the so-called loss on solution and no need to add a deflocculating agent. The sodium taken up from the sodium hypobromite is sufficient to ensure deflocculation, even for soils containing calcium carbonate. The method has also been applied successfully to soils containing gypsum. The solubility of gypsum in $N \mathrm{NaCl}$ is about four times as great as that in water; considerable amounts may therefore be removed by prolonging the washing with $N \mathrm{NaCl}$ and small amounts of gypsum in the final suspension have less flocculating effect on the sodium clay than on suspensions of ammonium clay.

\section{COMPARISON OF METHODS.}

The sodium hypobromite method was compared with the International $\mathrm{A}$ method $\left(\mathrm{H}_{2} \mathrm{O}_{2}, \mathrm{HCl}, \mathrm{NH}_{4} \mathrm{OH}\right.$ treatments) and with Puri's method (3), in which the only pretreatment is with $N \mathrm{NaCl}$ followed by the addition of small amounts of $\mathrm{NaOH}$ to the final suspension. A 2 per cent. soil suspension was used throughout, even though this appears to be too high for accurate separation of clay in soils containing large amounts of clay and silt. A 20 c.c. pipette with a straight tip was employed.

Up to the present tests have been made on 25 soils from several countries, most of them chosen as difficult to analyse by one or other of the common methods. 
All results are given as percentages of the original air dry soil and both the oven dry and the ignited weights of fractions are given. Although the former are generally preferred, the ignited weights are better for comparing the degrees of dispersion secured by different methods when varying amounts of organic matter may be left in the fractions or when the clays may differ in hydration (e.g. $\mathrm{Na}$-clay and $\mathrm{NH}_{4}$-clay). The clay and the silt fractions in methods omitting oxidation may contain considerable amounts of organic matter and an inefficient dispersion may be obscured.

Table I gives results by the three methods for the six samples used in the co-operative work of the First Commission of the International Society of Soil Science proposed after the Prague Conference 1929 and reported to the Leningrad Congress in 1930, together with those for three additional Sudan soils. Only in one of these soils (No. 6, Zagreb; loss on ignition 8.6 per cent.) is there any appreciable difference between the $\mathrm{NaCl}$ and the $\mathrm{NaBrO}$ method. It is unfortunate that all but one of the series of soils chosen for detailed work by the Commission should have had such low organic matter contents that oxidation was unnecessary. The $\mathrm{NaBrO}$ method gives higher results than the $\mathrm{H}_{2} \mathrm{O}_{2}$ method through the more effective dispersion of the sodium clay, especially in the Sudan soils.

Table II gives similar comparisons for five British soils with appreciable amounts of organic matter. Some form of oxidation is obviously essential for the analysis of such soils by the pipette method. Pretreatment with $\mathrm{NaCl}$ dispersed only from one-third to one-tenth of the clay and the undispersed clay was found not as silt but as fine sand. The dry clay fractions contained relatively large amounts of organic matter. The differences between the hydrogen peroxide and the sodium hypobromite methods were small. In all cases $\mathrm{NaBrO}$ gave the higher clay fractions, presumably on account of the greater dispersion of the sodium clay.

A fen soil with 37.7 per cent. loss on ignition was used in an extreme test of the $\mathrm{NaBrO}$ method (Table III). Oxidation by hydrogen peroxide was very protracted and required more than 400 c.c. of $\mathrm{H}_{2} \mathrm{O}_{2}$ spread over 2 days. With the normal amount of $\mathrm{NaBrO}$ the clay content was lower and the silt content higher than by the $\mathrm{H}_{2} \mathrm{O}_{2}$ method, but with twice the normal amount of bromine the results by the two methods agreed closely. The $\mathrm{NaBrO}$ method was, of course, much simpler and more convenient to carry out. In spite of the large organic matter content of this soil pretreatment without oxidation was sufficient to disperse almost all the 


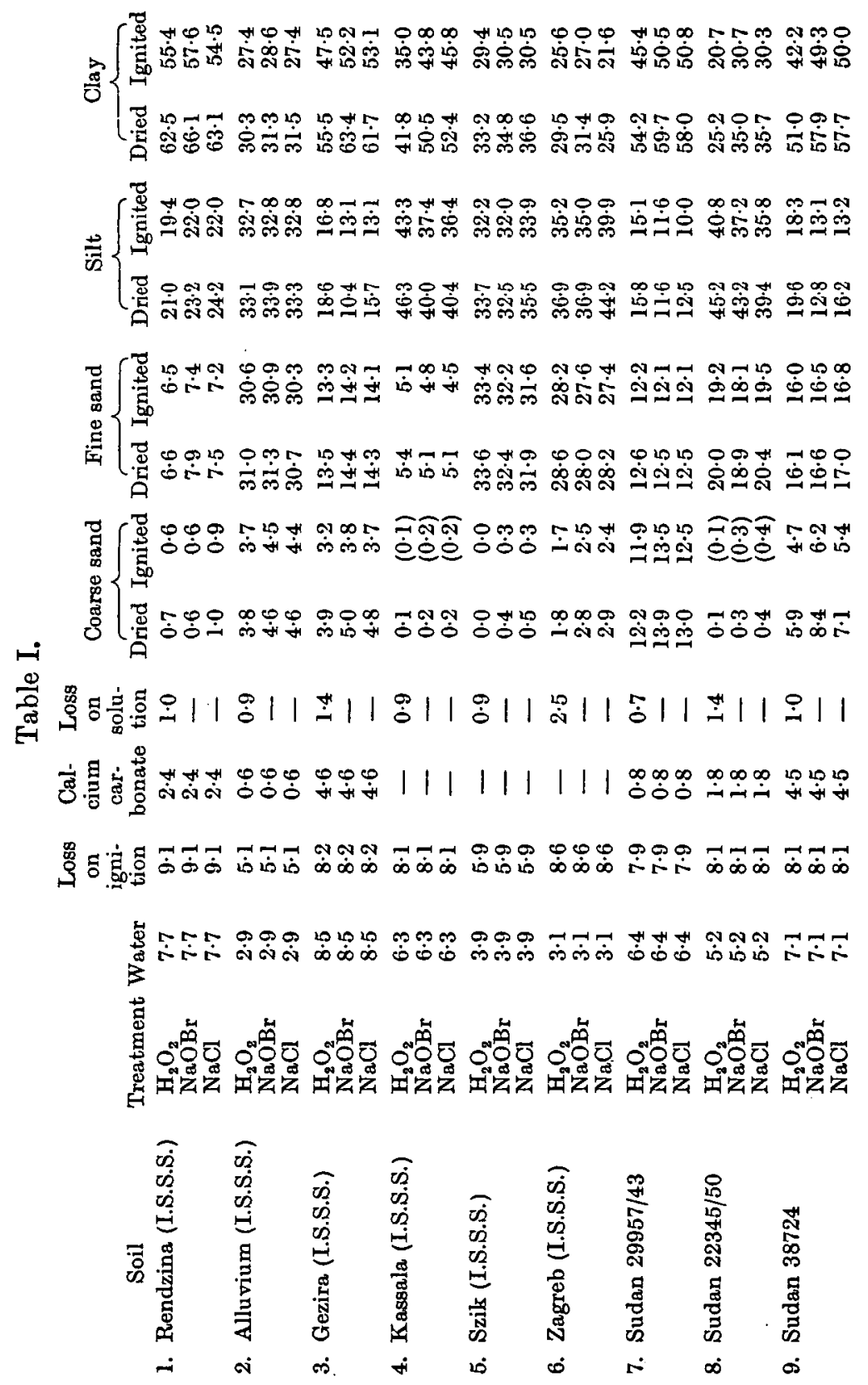




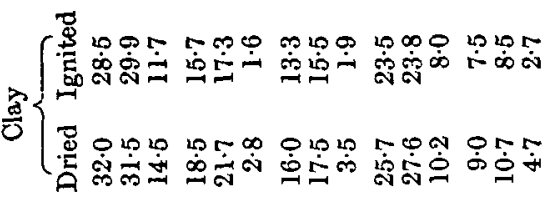

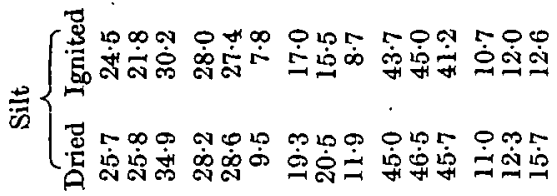

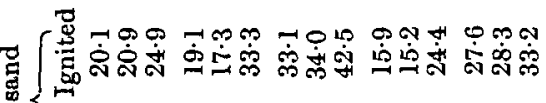
$\sum_{1}$ 范

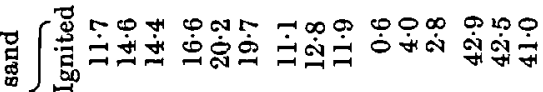

怨

J

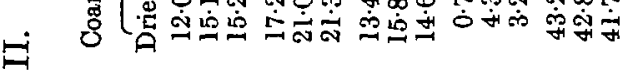

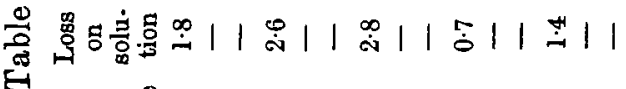

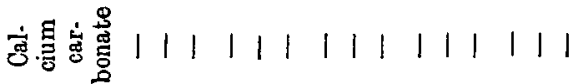

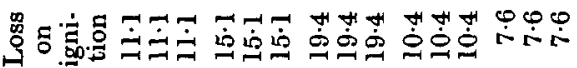
\$ั (3)

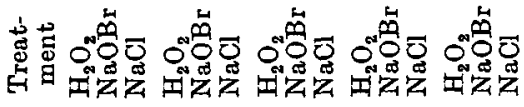

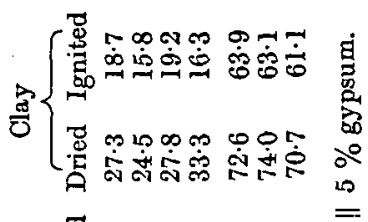

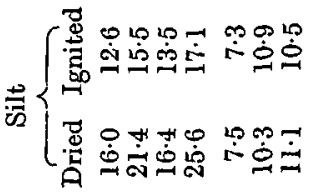

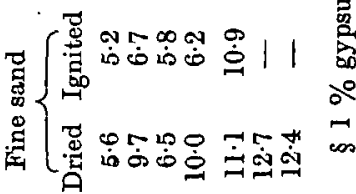

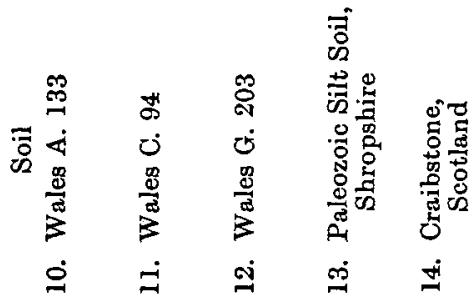

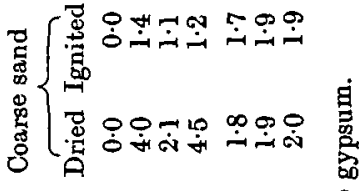

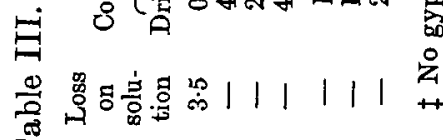

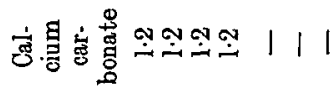

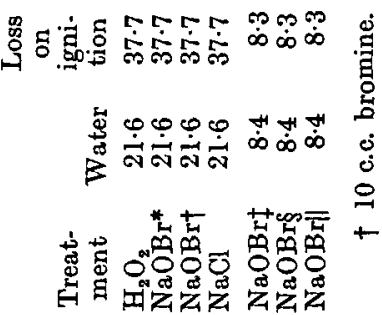
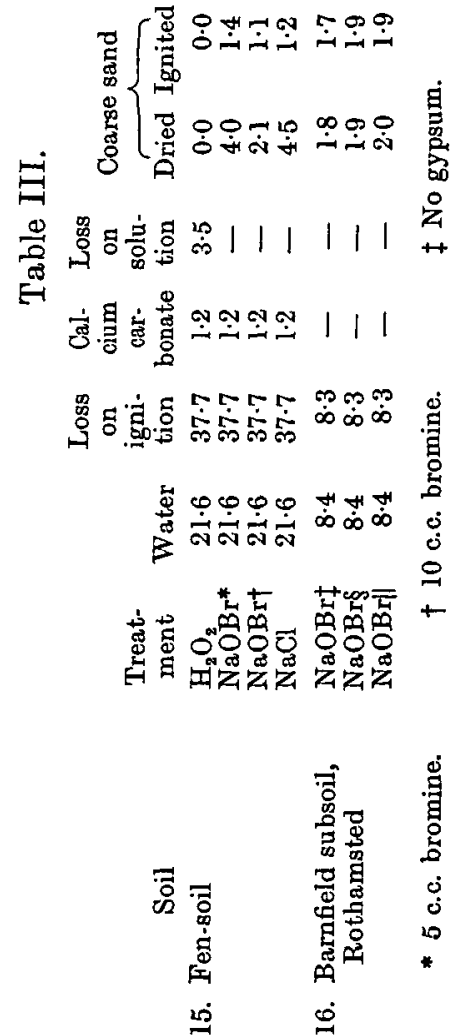


\section{Sodium Hypobromite Method for Mechanical Analysis}

clay, but oven dry weights of clay and silt fractions were misleading; one-half of the clay fraction was volatile.

Oxidation is required in some soils to secure efficient dispersion and in others to prevent the inclusion of indefinite amounts of organic colloids in the clay fraction. It may happen that these two opposite effects will cancel out within the limits of accuracy usually required and so account for some of the cases in which preliminary oxidation was not found necessary.

The data given above are sufficient to show that the organic matter content alone does not determine whether or not oxidation is necessary to secure complete dispersion of the clay. As is shown in Tables I and II, the $\mathrm{NaCl}$ method failed to give complete dispersion of clay in soils 6 and 14 (with losses on ignition of 8.6 and 7.6 per cent. respectively), but succeeded with six other soils in Table I with 8 to 9 per cent. loss on ignition and with the fen soil with 37.7 per cent. loss on ignition. In a paper presented to the Leningrad meeting of the First Commission of the International Society of Soil Science, E. M. Crowther and E. Troell (4) suggested that oxidation is necessary for complete dispersion of the clay when the ratio of organic colloids (or total colloids) to the inorganic colloids (i.e. clay fraction) is high. Since the loss on ignition of the total soil (corrected for carbonates) depends on both organic and inorganic colloids, and the air dry moisture content depends primarily on the clay content and both of these quantities are commonly determined in conjunction with mechanical analyses, it was suggested that their ratio might be used to indicate the necessity for including oxidation in the pretreatment for mechanical analyses. Where the ratio of loss on ignition to air dry moisture content was more than $2 \cdot 5$, oxidation proved essential for complete dispersion of the clay in all soils tested.

The $\mathrm{NaBrO}$ pretreatment provides a useful method for removing humic material from soils in the preparation of representative samples of the inorganic colloids and for other purposes in which it is desired to avoid heating or decomposition.

\section{SUMmary.}

1. The use of freshly prepared solutions of sodium hypobromite instead of boiling hydrogen peroxide solutions in the pretreatment of soils for mechanical analysis by the pipette method has the following advantages:

(a) Soils containing manganese dioxide or large amounts of organic matter may be oxidised rapidly without heat, whereas oxidation of such 
soils by hydrogen peroxide is a tedious operation requiring large amounts of reagent.

(b) Possible changes in the clay through heating and the dissolution of considerable amounts of sesquioxides are avoided.

(c) The reagents are cheaper and more stable, especially in the tropics.

(d) It makes possible further simplification in the technique of mechanical analysis.

2. A new and more convenient method of mechanical analysis is proposed in which acid treatment and the addition of a special deflocculating agent are unnecessary, the time of shaking is greatly reduced, and the separation of the coarser fractions is made more precise. Where the results differ from those by the hydrogen peroxide method they may. be explained by the more effective dispersion of the sodium clay used in the proposed method.

3. It is shown that oxidation is required for complete dispersion in soils in which there is a high ratio of organic to inorganic colloids.

\section{ACKNowledgments.}

The author wishes to express his thanks to the Ramsay Memorial Fellowship Trust and to Sir John Russell for the opportunity to carry out this investigation in the Rothamsted Experimental Station; to Dr E. M. Crowther, Head of the Chemistry Department, for his interest and suggestions throughout the work; and to Prof. G. W. Robinson for supplying several of the soil samples.

\section{REFERENCES.}

(1) U.S. Dept. Agric. Tech. Bull. (1930), 170.

(2) Intern. Mitt. Bodenk. (1912), 7, 315.

(3) Mem. Dept. Agric. Ind. Chem. Series (1929), 10, 209.

(4) Proc. Second Intern. Soil Congress, Leningrad (1930) (in the press).

(Received March 7th, 1931.) 